\title{
¿TRADICIÓN MÚLTIPLE EN LA LEXICOGRAFÍA VASCO-LATINO- ROMÁNICA? ALGUNAS NOTAS SOBRE EL COMPONENTE FRASEOLÓGICO EN DICCIONARIOS BILINGÜES Y TRILINGÜES DE LOS SIGLOS XVI AL XVIII: DE NICOLAS LANDUCHIO (1562) A Jose MARia Aizpitarte (C. 1785) ${ }^{1}$
}

\author{
$M^{a}$ Teresa Echenique Elizondo \\ Universidad de Valencia
}

RESUMEN

El estrecho contacto de la lengua vasca con lenguas románicas a lo largo del tiempo ha tenido profundas consecuencias en el léxico e historiografia de ambos campos. El objeto del presente articulo es reconstruir de forma actualizada la tradición románica (principalmente castellana) contenida en los diccionarios bilingües y multilingües de ámbito vasco pertenecientes a los siglos XVI al XVIII. Dada la amplitud de información contenida en tales diccionarios, a la que se suma la escasez de trabajos previos en esta línea de investigación, la inserción de unidades fraseológicas del español sirve como guía, en el presente estudio, para sugerir posibles itinerarios transitados por tradiciones lexicográficas diversas hasta su integración en los diccionarios vascos de esa época hoy conocidos.

Palabras clave: Lexicografía vasca y románica - Diccionarios históricos bilingües y multilingües - Fraseología y Fraseografia.

ABSTRACT

The thousand years of intense contact with Romance languages have had a profound effect upon the vocabulary and the Lexicography of Basque. The aim of this work is to reconstruct, in an updated way, the sources of the Romance languages (principally Castilian) contained in the historical Basque dictionaries from XVI to $X V I I I$ centuries in order to determine how many lexicographical traditions have been integrated in the bilingual and multilingual dictionaries of the Basque Historiography itself. Although there is no doubt that dictionaries contain useful information, Phraseology has been considered this time a convenient approach to establish new perspectives in Hispanic lexicographical inquiry.

Keywords: Basque and Romance Lexicography - Bilingual and multilingual historical dictionaries - Phraseology and Phraseography.

\footnotetext{
${ }^{1}$ Este trabajo se inscribe en el proyecto de investigación HUM2005-02879/FILO "Historia, codificación y fijeza de las locuciones adverbiales en un segmento temporal del español (1492-1596)" del Ministerio de Educación y Ciencia.
} 
1. La historia de la lexicografía española, al igual que su historiografía en general, no ha sido ajena a la existencia de otras lenguas, además de la castellana, en territorio peninsular. Los diccionarios bilingües o plurilingües pueden ser, de facto, reflejo del contacto lingüístico habido en España, a excepción de los casos en que alguna de las lenguas incluidas no es propia de la Península Ibérica; habría que exceptuar de entre ellas, claro está, al latín, cuya inserción en diccionarios de esta índole obedece a razones de otro orden, entre las cuales no es la menos significativa el haber dado origen a casi todas ellas.

1.1. Ha sido, pues, la contigüidad lingüística en el espacio geográfico peninsular causa de la presencia de más de una lengua en la lexicografía española en numerosas ocasiones; de ahí que diccionarios bilingües o multilingües, que contengan también la lengua castellana, presenten características, no suficientemente analizadas todavía ${ }^{2}$, que deben guiarnos al establecimiento de una tipología adecuada que permita clasificarlos convenientemente como diccionarios monolingües, bilingües, semi-bilingües, bilingües traducidos, trilingües, multilingües, colecciones lexicográficas plurilingües o de otro tipo. El hecho de que algunos diccionarios trilingües vengan a resultar bilingües en la práctica, o incluso monolingües, al utilizar la presencia de la otra u otras lenguas como auxiliares para la única realmente central, no puede resolverse simplemente apelando a su caracterización como "falsos bilingües o falsos trilingües", pues los tipos subyacentes pueden obedecer a configuraciones estructurales susceptibles de ser distinguidas con claridad.

Estas consideraciones iniciales no son gratuitas, ya que afectan al contenido nuclear del presente trabajo. De hecho, hay un tipo de diccionario trilingüe que tiene su propia estructura, bien diferenciada del diccionario multilingüe "estándar", y es aquél en el que se contiene una lengua común a otras dos abarcadas, a su vez, en su territorio geográfico; entonces, la lengua común desempeña un papel distinto al de la mera equivalencia, papel que podríamos denominar solapado o superpuesto. A partir de esta consideración podríamos distinguir diccionarios que sólo recogen lenguas próximas y hasta coincidentes en el espacio y tiempo, o diccionarios que combinan lenguas alejadas entre sí en su dimensión espacial. La presencia del latín, desde esta perspectiva, implica la superación de la categoría espacio-temporal, hecho que tiene una relevancia significativa y propia en los siglos que nos ocupan. De lo dicho hasta aquí se infiere que falsos diccionarios trilingües deben ser considerados aquellos en que una de las lenguas incluidas es un mero adorno sin que su presencia sea en absoluto necesaria, lo que no quiere decir que no encierre información léxica y gramatical de interés: el Diccionario Trilingüe del Castellano, Bascuence y Latín de Manuel de Larramendi podría ser considerado uno de ellos; en cambio, en los diccionarios trilingües solapados o superpuestos las tres lenguas son necesarias para el objetivo marcado, si bien la parte que afecta a una de ellas puede haber sido elaborada por autor diferente, como parece suceder con la parte francesa del Diccionario Vasco-Español-Francés de Azkue, o puede responder a una tradición lexicográfica distinta, como es el caso de L'interprect ou traduction du Français, Español \& Basque de Voltoire o el Dictionarium latino-cantabricum de Pierre d'Urte. Con el fin de apoyar estas reflexiones básicas en torno al cometido de estas páginas, no estará de más recordar circunstancias históricas que afectan a la geolingüística vascongada.

\footnotetext{
${ }^{2}$ V. Echenique Elizondo (1998)
} 
1.2. La lengua vasca se habla hoy en un territorio que se extiende a uno y otro lado de la frontera franco-española y se caracteriza por una acusada complejidad sociolingüística derivada de la existencia histórica de varias lenguas en contacto: castellano en el lado peninsular, así como francés y occitano (gascón) en el continental en la actualidad, pero, hasta donde nos es dado remontarnos en el pasado, ha habido también gascón, occitano, francés (desde el siglo XVI), castellano, navarro, aragonés y (al menos en parte) catalán, pues su espacio ha venido comprimiéndose continuadamente en el transcurso de los siglos incluso en época histórica más o menos reciente ${ }^{3}$. Su distribución dialectal, por otro lado, es bien conocida de tiempo atrás; no ha existido una lengua vasca codificada homogéneamente para la totalidad de sus hablantes hasta época reciente (más concretamente, hasta fines del siglo XX), por lo que los textos escritos, conservados desde el siglo XVI, han dejado valioso testimonio de sus diferentes y variados dialectos ${ }^{4}$.

Podríamos definir este territorio, por lo tanto, como un espacio "transnacional",5 caracterizado por la existencia de una lengua antigua que no es neolatina, ni siquiera indoeuropea, que seguramente ha constituido durante largo tiempo un verdadero "espacio comunicativo" con independencia de la configuración política en la que ha permanecido inserto. La historiografía vasco-románica, por lo tanto, no es simplemente la suma de vasco + románico, sino la derivada del solapamiento experimentado por la implicación comunicativa habida en un territorio en el que se hablan varias lenguas desde hace largo tiempo, una de las cuales, la lengua vasca, abarca la extensión que han tenido y tienen otras varias románicas desde el momento mismo de su emergencia a partir del latín. En tiempos históricos más cercanos, la complejidad de ese espacio comunicativo se ha caracterizado por la presencia de una lengua, el vascuence, en territorio geográfico correspondiente a dos naciones diferentes, España y Francia, las cuales tienen, a su vez, sus lenguas oficiales (español y francés), además de otras, reconocidas en grado y cronología diversos en territorios parciales.

El plurilingüismo territorial, entendido como coexistencia de varias lenguas en una comunidad carente de plurilingüismo institucional ${ }^{7}$, en el que queda delineada, por lo tanto, una determinada unidad cultural sobre el fundamento de una lengua común, ha sido el caso del contacto vasco-románico hasta época reciente ${ }^{8}$ y es importante tomar en consideración este hecho a la hora de analizar la tradición lexicográfica de área vascongada, en la que hay puntos de partida muy diferentes en el método y elaboración de diccionarios. No hay frontera lingüística en área euskérica en la actualidad, así como tampoco ha existido en el pasado, allí donde la hay o la ha habido entre variedades romances, en tanto en cuanto nos es dado establecer una diferenciación tal dentro del continuum románico. Por lo tanto, el

\footnotetext{
${ }^{3}$ Hay noticia de que así ha sucedido desde el siglo XVI al XX; la situación podría haber variado en el lapso temporal transcurrido del siglo XXI, si bien estamos aún faltos de la perspectiva histórica que permita valorar adecuadamente ese cambio.

${ }^{4}$ V. Michelena (1988) y Zuazo (2008).

${ }^{5}$ V. Krefeld (2007: 67-69).

${ }^{6}$ Ibídem.

${ }^{7}$ V. Holtus (1994: 151-157) y Echenique (1998, passim).

${ }^{8} \mathrm{Y}$ sigue siéndolo por lo que respecta a Francia.
} 
concepto de frontera lingüística en área vasco-románica queda solapado, y lo hace en forma múltiple y de manera muy compleja desde una perspectiva sociolingüística ${ }^{9}$, por la presencia del euskera junto al gascón, francés y castellano, en la actualidad, y del gascón, occitano, navarro, aragonés y catalán, en el pasado; y en esa(s) frontera(s) hay que incluir también la lengua latina en una doble dimensión: la que afecta, de un lado, al elemento latino-románico de estrato antiguo inserto en los diferentes dialectos vascos, con soluciones propias así mismo diversas (González Ollé 2004 y Echenique en prensa-c), y al latín como elemento cultural de primer orden, a la par que fuente de enriquecimiento para los escritores vascos ante la falta de recurso a un modelo antiguo propio, de otra.

En relación con esto último es importante recordar que, en el proceso de creación de tradiciones discursivas en lengua vasca, el latín está presente de forma notable en escritores vascos de los siglos XVI y XVII como Bernard Dechepare ${ }^{10}$, Johannes Leizarraga, Joannes de Etcheberri o Juan de Tartas, en los que encontramos profusión de latinismos como infidelitate, creatione, scriptura al lado de otras voces latinas o romances que presentan una mayor integración histórica vasco-románica, como es el caso de sperança, scribatu 'escribir' y un largo etcétera ${ }^{11}$.

1.3. Cuando se acomete, pues, la empresa de crear tales tradiciones discursivas en lengua escrita, impulsada en buena medida por la Reforma, la lengua vasca carece de modelos culturales propios sobre los cuales forjarse, pues hasta entonces se había movido en el contexto de la cultura oral, donde hubo antes, y habrá después, larga tradición; así se explica que la lengua escrita trate de constituirse mirando a modelos latinos y románicos, utilizando la scripta románica, primero navarra y gascona, así como también castellana y francesa más tarde. La Reforma no triunfó en territorio vasco, pero dio lugar, como contrapartida, a la preocupación del clero católico por catequizar a los feligreses en lengua vulgar, lo que explica la proliferación de catecismos en vascuence o bilingües.

La lexicografía vasca, por su parte, surge en el siglo XVI y, entre los siglos XVI al XVIII, se muestra también estrechamente vinculada a otras lenguas, principalmente aunque no sólo- románicas. En alguna ocasión he señalado que la parte románica incluida en la lexicografía vasca es prácticamente desconocida ${ }^{12}$ y creo poder hacer esta afirmación sin temor a errar. En efecto, así como la atención prestada a la Lexicografía del euskera desde la vertiente de la Filología Vasca ha sido grande en los últimos años, a la par que ha dado lugar a resultados de gran calado ${ }^{13}$, no ha sucedido lo mismo con la tradición lexicográfica latina y románica contenida en la lexicografía vasca.

\footnotetext{
${ }^{9}$ Es de sobra conocida la variedad de situaciones implicadas en el contacto de la lengua vasca con la castellana, la francesa y otras, que han perdurado durante siglos.

${ }^{10}$ Cuya obra, primera para la tradición escrita en euskera (Burdeos, 1545), queda rotulada como: Linguae Vasconum Primitiae.

${ }^{11}$ V. Echenique y Sánchez (1997: 161-168).

${ }^{12}$ V. Echenique (1995).

13 Entre los que ocupan lugar destacado los trabajos pioneros de Luis Michelena (Michelena y Agud 1957, Michelena 1970, Michelena y Sarasola 1987-2004), así como las primeras investigaciones llevadas a cabo bajo su magisterio (Altuna 1979 y otros; Knörr 1987 y otros; Lakarra 1992, 1993, 1995 y otros; Sarasola 1980, 2008 y otros; Urquizu 1989 y otros, por citar algunos de los que han tenido mayor impacto) o derivados de él (Urgell
} 
Aparte el componente glosográfico, las referencias al léxico del vascuence en el Fuero General de Navarra, la documentación de monasterios como Irache, Leire y demás actividad lexicográfica durante la Edad Media en los que nos es dado observar casos de equivalencia en el léxico vasco y románico, hoy es conocida la existencia de diccionarios históricos de la lengua vasca de donde se ha extraído la información pertinente y bien contrastada para reconstruir la historia del léxico vasco en el conjunto de su implantación geográfica, y en ocasiones también social, a través de los tiempos. Esta línea de investigación, de matriz micheleniana, está impulsada por el deseo de indagar en la historia de la lengua vasca, como consecuencia natural de su motivación primera, en tanto que la parte no vasca en el estudio de estos diccionarios ha sido considerada, en el mejor de los casos, como tarea secundaria, si bien hay excepciones de interés que habría que ir integrando en un estudio más sistemático ${ }^{14}$; por alguna causa aún no bien determinada, la tradición española no les ha prestado la atención que cabría otorgarles.

1.4. Bien es verdad que no han llegado a recuperarse diccionarios de cuya existencia en época pasada hay datos fehacientes: en la etapa que se conoce como prelarramendiana, esto es, anterior a la publicación del Diccionario Trilingüe del Castellano, Bascuence y Latín $(D T C B L)$ de Manuel de Larramendi (San Sebastián, 1745), sabemos que Etxeberri de Ziburu (nacido h.1580 y muerto h.1664) dedicó un diccionario al euskera, y otro Jacques Bela (1586-1667); y que Dominique Bidegarai (?-1679) elaboró un diccionario vascolatino-francés (completado finalmente con el castellano). Más sorprendente resulta la noticia del diccionario trilingüe tagalo-castellano-cántabro escrito por Fr. Melchor de Oyanguren, guipuzcoano que estuvo en Filipinas y pasó a ser superior del convento mexicano de San Agustín de las Cuevas en 1747, autor también, en la primera mitad del siglo XVIII, del conservado Arte de la lengua japona, dividido en quatro libros según el arte de Nebrija ${ }^{15}$, que debió coincidir en el tiempo con el llevado a cabo por Pierre Duhalde, ninguno de los cuales se nos ha conservado, aunque no es disparatado pensar en la posibilidad de que algún día se encuentre algún ejemplar hoy perdido. La filiación de estos diccionarios, que no han llegado hasta nosotros, respecto de la lexicografía romance ya existente (que es, en buena medida, huella de la tradición nebrisense aplicada al campo vasco) queda, hoy por hoy, como materia puramente especulativa.

Por fortuna, conservamos otros diccionarios, de los que algo vamos sabiendo en los últimos tiempos. De 1562 data el Dictionarium Linguae Cantabricae de Nicholaus Landuchius, cuya deuda con Nebrija fue ya indicada por A. Gallina ${ }^{16}$. Nicholaus Landuchius o Landucci, italiano buen conocedor de lenguas, escribió en el año 1562 un

1998a, 1998b, 1999, 2000, 2004, 2008 y otros), que han tenido continuación fructífera en alto grado. Hay información de interés actualizada en R. Gómez (2008: 341-342)

${ }^{14} \mathrm{~V}$., por poner algún ejemplo, la referencia a la estela de C. Oudin en la lexicografía vasca (Kerejeta 1991), deudor, a su vez, de Covarrubias (v. Verdonk 1979 y Lépinette 1992) o el contraste con Autoridades en el Trilingüe de Larramendi (Urgell 1999).

${ }^{15}$ V. Oyharçabal (1989: 59-73), Alvar (1997: 37-51, quien, además de estudiar la tradición lexicográfica en la que se inserta, explica que recurrió al vasco a la hora de aclarar determinadas particularidades del japonés, si bien no menciona el diccionario tagalo-castellano-cántabro; sí recuerda que estuvo en Filipinas en 1717 y 1723) y Gómez (2008: 341-342).

${ }^{16}$ V. Gallina (1959: 129). 
vocabulario español, italiano, francés y vizcaíno de 328 folios, publicado por M. Agud y L. Michelena ${ }^{17}$, que se encuentra en la Biblioteca Nacional de Madrid; es el primer trabajo lexicográfico de una cierta extensión conocido que incluye el vasco, cuyo título en euskera reza: Bocabularioa ezqueraz jaquiteco, eta esqueraz verba eguiteco ('Vocabulario para saber [sic] en euskera y para hablar en euskera'), indicador por sí mismo de su finalidad como método para los no vascohablantes. Su valor real como reflejo de la lengua vasca es dudoso, si bien, tras la aparición de nuevos testimonios vascos del siglo XVI, es susceptible de recibir una interpretación más positiva, tal como Koldo Mitxelena (Luis Michelena) sugirió en el prólogo a su edición. Aunque permaneció inédito durante siglos, era conocido, al tiempo que fue duramente criticado, por Manuel de Larramendi y otros vascólogos. La modalidad de euskera que contiene, calificada de "muy discutible"18, no nos interesa hoy aquí; sí, en cambio, las posibilidades que depara para la lexicografía romance. Larramendi dice en su trilingüe que esta pieza ${ }^{19}$ acreditaría a su desconocido autor de "muy mal Bascongado, y no muy buen Castellano" ${ }^{20}$. Por su parte, Julio de Urquijo, que se hizo con una reproducción fotográfica del ejemplar conservado en la Biblioteca Nacional, señala ${ }^{21}$ : "Abunda en erderismos ${ }^{22}$ y Larramendi lo trató por esta razón con gran desprecio. Hay, sin embargo, que tenerlo en cuenta, no solamente por la fecha (1562), sino porque además de traer algunas palabras que no se encuentran en otros diccionarios, nos permite estudiar las transformaciones que en el siglo XVI experimentaban las palabras castellanas en boca vizcaina"23. Estas observaciones parecen haber caído en saco roto, salvo en contadas ocasiones, hasta el día de hoy. Michelena, que, en la edición conjunta del diccionario preparada con M. Agud, hace una detallada exégesis de la documentación vasca recogida en Landuchio y apunta algún detalle sobre el descuidado romance o su localización ${ }^{24}$, afirma: "No parece aventurado, por todo ello, suponer que las traducciones de la lista castellana de Landuchio proceden de una población importante, con tradición eclesiástica, donde había personas que a mediados del siglo XVI conocían poco o mal el vascuence" ${ }^{\text {"2 }}$. Michelena se refiere a las traducciones al vasco, pero esas mismas personas eran poseedoras de un castellano peculiar (tal como documenta Landuchio), que habría que reconstruir y que Michelena imagina emplazado en lugar no lejano a Vitoria por razones relativas a la lengua vasca en él contenida, así como por ciertas resonancias del propio romance $^{26}$. De las 6000 entradas castellanas (grosso modo), la mayor parte de las cuales no tiene equivalencias vascas a partir de la letra $\mathrm{S}$, y de cuya filiación nebrisense hizo ya

\footnotetext{
${ }^{17}$ Dictionarium Linguae Cantabricae (1562), San Sebastián, Diputación de Guipúzcoa, 1958.

${ }^{18}$ Michelena, "Introducción” de la edición conjunta con Agud (pág. 8).

19 "Este corto Vocabulario [...] enquadernado juntamente con otros dos, que le prenden, de la lengua Italiana, y Francesa" (I, p. XXXV).

${ }^{20}$ La cursiva es mía.

${ }^{21}$ V. Urquijo (1925: 486, n. 2).

${ }^{22}$ Entiéndase 'castellanismos' en este caso.

${ }^{23}$ La cursiva es mía.

${ }^{24}$ V., por ejemplo, Michelena y Agud (1958: 18-19, n. 11, o 39-48).

${ }^{25}$ V. Michelena y Agud (1958: 47).

${ }^{26}$ La tímida apelación a la organización gremial de la Edad Media o a la memoria de la población judía (v. Michelena y Agud 1958: 48) sigue siendo, en cualquier caso, muy sugerente.
} 
mención A. Gallina en el trabajo citado, se puede destacar, en un repaso apresurado que necesitaría de análisis más detallado y minucioso, que, junto a palabras para las que Landuchio no encontró traducción vasca por razones más o menos comprensibles a primera vista (pecoso, pesebre, poyo, reja, reprobación, salamanquesa y tantas otras), hay notas de valor variable que no habría que desdeñar: sastre se vierte al euskera como dendaria, en tanto encontramos sastra muger sin equivalencia en vasco ${ }^{27}$; calongia aparece vertido al vasco como canongia, costurera como jozquina ${ }^{28}$, cirujano como barberoa, ñudo como orapina, además de ñudo, ñudo hazer, ñublado, ñublosa cosa, ñublo de pan [sic] (las dos últimas voces sin correspondencias en euskera), orosuss [sic] como erregaliza, todas las cuales merecen un estudio minucioso desde la perspectiva románica ${ }^{29}$.

Hacia 1620 debió ver lan luz en Lyon por primera vez L'interprect ou Traduction da François, Espagnol \& Basque de Voltoire, publicado después en Bayona en 1642 como Tresor hirour lenguaietaqua francesa, espagnola eta hesquara, que no es un diccionario, sino una gramática que contiene en su parte final una breve lista de palabras ${ }^{30}$. Aún inédito permanece el diccionario manuscrito vasco-francés y parcialmente latín-castellano que Silvain Pouvreau elaboró en $1675^{31}$, o sin nueva edición los Vocabularios vasco-francés y francés-vasco que al final de su Gramatica escuaraz eta francesez composatua francez hizcunça ikhasi dutenen faboretan aparecieron en Bayona en 1741 debidos a Martin Harriet.

No así el Dictionarium latino-cantabricum (Londres, 1715) de Pierre d'Urte ${ }^{32}$ : en este diccionario no está presente el español de forma directa, pues es un diccionario unidireccional latín-vasco, pero en la documentación del propio vascuence resulta visible el elemento latino y románico en ella inserto, por lo que cabría recurrir a él para obtener información de interés de la parte neolatina, tarea que aún no ha tenido emprendedores; por lo que respecta al latín, parece seguir la estela de Du Cange en parte, si bien no en su totalidad, por lo que no habría que desdeñar la posible influencia del Calepino; pero, como señala Urkizu ${ }^{33}$, dado que Urte elaboró su diccionario en Londres, no es descartable que su parte latina sea deudora de la tradición lexicográfica británica. Frente al diccionario de Landuchio, en que el análisis gramatical está menos presente, al menos como intención explícita, y lo que ofrece es una tabla de correspondencias léxicas con finalidad traductiva,

\footnotetext{
${ }^{27}$ Cuya mención (deudora de Nebrija) no responde al mismo origen de la equivalencia de ydolatra por andra ydolatrea 'mujer idólatra' señalada por Michelena con su conocido sentido del humor ("Para él [Landuchio], por lo visto, no había idólatras más que del sexo femenino", Michelena y Agud 1958: 18-19, n. 2).

${ }^{28}$ Femenino de origen románico, al igual que otros casos en los que el vascuence ha suplido por procedimientos de este origen la ausencia de género gramatical, que no es para Landuchio lo mismo que sastra, según acabamos de ver.

${ }^{29}$ Véase también Michelena (1958: 37), así como Lakarra (1995: 16, n. 53).

${ }^{30}$ Por esa razón no trataré de él en el presente trabajo, aunque conviene recordar su existencia para investigaciones futuras con el fin de estudiar a qué tradición pertenece la parte castellana o de qué diccionarios o gramáticas es deudor. Véase Lakarra (1995: 10-11).

${ }^{31}$ V. Michelena (1970), Azcarate (1991) y Kerejeta (1991).

${ }^{32}$ V. Urkizu (1989) y Lakarra (1992), entre otros.

${ }^{33}$ V. Urkizu (1989, I: 94).
} 
el de Urte representa un progreso en el camino hacia la inserción de información gramatical en su estructura.

No es casual que el diccionario histórico de mayor envergadura dedicado a la lengua vasca en otros tiempos lleve por título Diccionario Trilingüe del Castellano, Bascuence y Latin (1745), y no lo es porque Larramendi se inserta en una corriente lexicográfica peninsular dieciochesca en la que el multilingüismo es moneda corriente ${ }^{34}$. Manuel de Larramendi, autor también de un Diccionario Vasco-Castellano ${ }^{35}$, era buen conocedor del euskera, y la preocupación por dejar bien sentada la defensa de la lengua vasca ante un público lector castellano parece constituir claro motor de sus tareas filológicas. En realidad, Larramendi, con su actividad apologista (es bien conocida su polémica con Gregorio Mayans sobre la antigüedad de la lengua vasca) propició el resurgimiento de la literatura vasca escrita en territorio peninsular, que, en este siglo, obtiene frutos superiores a los que podemos encontrar en tierras continentales. En realidad, Larramendi abundó en la búsqueda de un fondo común a la convivencia milenaria vasco-castellana, en la que el latín habría podido servirle como elemento de referencia unitaria, pero, llevado seguramente por un exceso de vehemencia, llegó a la conclusión de que ese marco común a castellano y latín era el fondo vasco antiguo. Con ello conseguía poner de relieve la antigüedad del euskera en la Península, cosa desde luego cierta y que, además, constituía su interés primordial, al tiempo que hacía depender al castellano del vascuence, cuestión a todas luces mucho menos cierta. El latín queda, en su diccionario, sin función clara, ya que no se convierte en elemento abarcador de ambos, euskera y castellano, antes al contrario, es la lengua vasca la que pretende asumir este papel, si bien gracias a la presencia latina consigue evitar la confrontación bilateral castellano-euskera. Bien es verdad que Larramendi lleva a veces las cosas demasiado lejos haciendo depender también al latín del vascuence, pero sobre esta cuestión se han escrito ya páginas inmejorables ${ }^{36}$.

A partir de Larramendi, y además de los Suplementos al Diccionario Trilingüe de Larramendi de Joseph de Jesus Maria Araquistain, contamos con el Diccionario políglota francés-euskara-griego-céltico-árabe-latín-gótico-alemán-español-italiano de Chevalier de Bela, del que hay edición parcial en Pamplona ${ }^{37}$, el proyecto de un Gran Diccionario Vasco impulsado por Campomanes en $1773^{38}$ o el Euskara ta Gaztelaniazko Iztegia. Diccionario basco-castellano de Jose Maria Aizpitarte compuesto hacia $1785^{39}$. La explicación de este hecho está íntimamente relacionada con la aparición de la Sociedad Bascongada de los Amigos del País. Esta Sociedad, que más tarde recibirá el título de Real Sociedad Bascongada de los Amigos del País, pionera de las Sociedades de Amigos del País esparcidas por el mapa peninsular y apoyadas por la política ilustrada del gobierno de Carlos III, fue fundada en 1764 por Francisco Xabier María de Munibe, conde de Peñaflorida; por iniciativa de Pedro Rodríguez de Campomanes, llegó a concebirse el

\footnotetext{
${ }^{34}$ V. la útil catalogación hecha por Félix San Vicente (1995).

${ }^{35}$ Editado por P. Altuna, Euskera, 1967, 148-300.

${ }^{36}$ V. Michelena (1970).

${ }^{37}$ A cargo de Txomin Peillen (1983).

${ }^{38}$ V. Echenique (1985).

${ }^{39}$ V. Altuna (1985).
} 
proyecto para un gran diccionario vasco, planeado como obra colectiva e inspirado, seguramente, en el Diccionario de autoridades de la Real Academia Española.

1.5. Llegados a este punto considero por completo necesario hacer referencia a una magna obra hoy ya concluida, el Diccionario General Vasco / Orotariko Euskal Hiztegia $(D G V)$ de L. Michelena e I. Sarasola, sin duda uno de los logros trascendentales de la Filología Vasca de los últimos tiempos, equiparable a un Thesaurus y, en todo caso, de capital importancia para la lexicografía y lexicología vascas, así como instrumento de indudable valor para el romanista que desee acceder a ellas. El $D G V$ surgió como encargo de la Academia de la lengua Vasca a L. Michelena por la necesidad sentida de renovación de contenido y método del Diccionario Vasco-español-Francés que R. M. Azkue había llevado a cabo a principios del siglo XX; gracias a él tenemos una visión contrastada, palabra por palabra, de la historia particular de todas y cada una de las voces de la lengua vasca desde sus primeras documentaciones hasta el año 1970 en que se institucionaliza la lengua común conocida como euskera batua, con lo que la lengua vasca emprende una etapa de normalización que dota a sus testimonios de cierto carácter tutelado, si bien con altas dosis de flexibilidad, en su área de implantación. Puede ser una excelente obra de consulta para el no vascólogo, pues la redacción está efectuada en castellano, lo que permite su acceso al investigador no conocedor del euskera, si bien la ejemplificación, claro está, es vasca en su práctica totalidad y recoge todo el léxico vasco inserto en la tradición lexicográfica, así como también el léxico de otro origen (de ahí el interés) integrado en el vascuence. La parte del $D G V$ en la que se ha realizado el mayor esfuerzo es, sin duda, la que corresponde a los ejemplos de utilización por vascos de todas las épocas y ello porque se pretende ofrecer así una imagen fiel del amplio corpus de la tradición literaria y de la oral, que asciende a más de cuatro millones de palabras-texto de obras de todo tipo, época y dialecto hasta $1970^{40}$. Recoge la práctica totalidad de lo conocido sobre el euskera antes de 1970, con excepción de testimonios encontrados en época reciente, como puede ser el texto de Joan Perez de Lazarraga y algún otro. Hay gran volumen de información de los siglos XVI-XVIII, con integración de las obras lexicográficas de ámbito vasco, gramáticas acompañadas de vocabularios y otra serie de muestras de gran trascendencia para el estudio léxico y gramatical. Se ha conjugado en él el carácter aparentemente trilingüe del DTCBL de Larramendi con el de un diccionario monolingüe general, con lo que queda convertido en un Diccionario general integral, esto es, un auténtico Thesaurus de la lengua vasca ${ }^{41}$. La huella de Joan Corominas, de quien Michelena fue recensor en el ámbito vasco y verdadero admirador (con aprecio y admiración correspondidos por parte de Corominas), desde la aparición del primer volumen de su DCELC y siguientes, resulta bien visible en la concepción de la obra y en su estructura, lo que permite hacerse una idea de la importancia que este diccionario entraña para el ámbito castellano, en particular, y románico, en general.

\footnotetext{
${ }^{40}$ Véase el prólogo de Sarasola.

${ }^{41}$ Merece destacarse el hecho de que, tras la abreviatura Etim., se da al final de los artículos (no de todos los posibles, ciertamente) las informaciones disponibles referentes al origen real o supuesto de la entrada léxica correspondiente, latinos o románicos en gran medida; quiere, con ello, ser una ayuda para un diccionario etimológico vasco, con carácter sin duda distinto a la intención que anima a los ya existentes de este carácter.
} 
La trayectoria de gran parte de los materiales que cito en el presente trabajo está, más o menos, contenida en $D G V$, aunque no siempre ${ }^{42} \mathrm{y}$, desde luego, la reflexión que guía este trabajo es, en todo caso, muy distinta a la que condujo a la elaboración del $D G V$, pues trata de rescatar la información relativa a la lengua castellana (al románico en sentido amplio), en tanto el $D G V$ tiene como hilo conductor el establecimiento de la historia del léxico vasco dirigido, en última instancia, a servir de guía para la confección de un diccionario vasco normativo, tarea institucional aún inacabada ${ }^{43}$, precisamente por la gran riqueza de materiales contenidos en $D G V$ y la dificultad derivada de decidir, caso por caso, la forma canónica para el léxico común. Me parece importante, no obstante, insistir en estas páginas sobre la idoneidad de esta obra para su aprovechamiento en el ámbito de la lexicografía romance de todas las épocas ${ }^{44}$.

2. La segunda parte del título del presente trabajo alude al tratamiento lexicográfico mostrado por unidades fraseológicas vascas y románicas. El punto de arranque para ello es múltiple: en primer lugar, quiere ser una forma de acotar un campo de estudio, demasiado amplio para poder ser abordado en su totalidad, ni siquiera de forma generalista, dirigiendo la atención hacia el campo de la fraseografía histórica. En segundo lugar, pretende subrayar la circunstancia de que, en muchos casos, las correspondencias entre unidades fraseológicas vascas de origen románico no se dan solamente entre vasco y español, sino también entre vasco, español y francés, y, además, latín; en estas páginas la atención va a ir dirigida preferentemente al castellano, por lo que me fijaré en la inserción lexicográfica que determinadas unidades pluriverbales castellanas han tenido en diccionarios de ámbito vasco entre los siglos XVI al XVIII. Finalmente, desearía contribuir a delimitar algunas pautas de estudio de la fraseología histórica española a través del análisis lexicográfico.

Antes de proceder a efectuar las consideraciones anunciadas, creo necesario aportar algunas reflexiones sobre el estudio fraseológico y fraseográfico en su dimensión diacrónica. Entre los varios objetivos de la investigación fraseológica del español se encuentra, sin duda, su aportación a la historia de la fraseología $a^{45}$. Por otra parte, aunque en estrecha vinculación con ello, en los numerosos trabajos de reflexión en torno a la fraseología española que se han publicado en los últimos veinte años se encuentra como lugar común la afirmación de que los estudios sobre las unidades fraseológicas del español han emergido con retraso y que, de cualquier forma, no han llegado a alcanzar suficiente

\footnotetext{
${ }^{42}$ Por ejemplo, en Larramendi aparece: "Vacilante, coloca dogoana, zalantzan. Lat. Vacillans, titubans", que DGV no cita; menciono este caso por el valor locucional de la correspondencia vasca de vacilante: coloca, zalantzan.

${ }^{43}$ Los resultados institucionales ya existentes son aún claramente incompletos; la carencia de un diccionario institucional de la lengua vasca no deja de ser llamativa por desconocida, si bien es verdad que hay excelentes diccionarios que cumplen satisfactoriamente la función normativa.

${ }^{44}$ Mencionaré el caso de DGV s.v. "APROPOS (V-gip), aprepos. Tr. Además de alguna vez en Tartas (pero cf. tb. aproposki), aparece en textos guipuzcoanos y vizcaínos desde mediados del s. XIX. 1. 'A propósito, de propósito, adrede' (Laurgarrena, emanen du arrazoiñak, hortik, hebetik, pundu hontara, iustoki eta apropos hedatzen, eta iuntatzen ahal denak. Tartas, Onsa, 14". Es curioso que se documente en vasco peninsular y no en Iparralde, de donde debe venir; el caso documentado en Tartas y recogido en $D G V$ ofrece gran relieve como para pensar que su testimonio único no es casual.

${ }^{45}$ V. los trabajos de Bargalló y Ginebra (2002), Montoro del Arco (2002), Martínez Montoro (2002), Martínez Alcalde y Quilis (2003), entre otros.
} 
calado si los comparamos con lo sucedido en otras lenguas. Considero que tiene razón plena García-Page ${ }^{46}$ cuando afirma que no está totalmente justificado hablar de retraso en la aparición de estudios fraseológicos del español y, mucho menos, de parquedad de los mismos, si bien es verdad que ha habido en los últimos años un florecimiento destacado de trabajos, así como de diccionarios, dedicados a las combinaciones fijas de palabras. En la actualidad contamos con recientes diccionarios de fraseología ${ }^{47}$, que son muestra de la estrecha implicación existente entre teoría fraseológica y praxis lexicográfica, además del interés que la inserción de unidades fraseológicas tiene desde el punto de vista metalexicográfico ${ }^{48}$, debido a la complejidad que representa la incorporación unitaria de unidades pluriverbales en la estructura habitual del diccionario. Desde hace tiempo ${ }^{49}$, así como también en época más reciente ${ }^{50}$, se ha atendido a los principios gramaticales que intervienen en la funcionalidad de las unidades fraseológicas, al tiempo que el auge de estudios en torno al análisis del discurso oral las ha convertido en elementos de relieve, además de haber servido como campo de pruebas para el estudio de los procesos de gramaticalización, sin olvidar la ayuda metodológica procedente de trabajos dedicados a las propiedades distribucionales y funciones pragmáticas de la llamadas partículas discursivas.

Cosa distinta es, eso sí, la investigación histórica en fraseología, que está aún hoy por hacer prácticamente en su totalidad ${ }^{51}$. En una obra reciente, fruto de la investigación seria y rigurosa de muchos años ${ }^{52}$, puede comprobarse hasta qué punto está desarrollado ya en la actualidad el análisis teórico dedicado a las locuciones adverbiales, en tanto resulta aún de gran precariedad su investigación en la perspectiva diacrónica ${ }^{53}$.

${ }^{46}$ V. García-Page (2008: 40-44)

${ }^{47}$ V. Seco, Andrés y Ramos (2004), Bosque (2004), Santos Río (2003), entre otros, sin olvidar los diccionarios de partículas discursivas emprendidos por Martín Zorraquino en Zaragoza o por Briz Gómez en Valencia.

${ }^{48}$ V. Wotjak (1998), Tristá Pérez (1999), Martín Zorraquino (2003), Haensch y Omeñaca (2005).

${ }^{49} \mathrm{~V}$. Thun (1978).

${ }^{50}$ V. Corpas (1996), Mendívil (1999), Montoro del Arco (2006), García-Page (2008).

${ }^{51}$ V. Echenique (2003, 2008b, 2008c y en prensa).

${ }^{52}$ V. García-Page (2008).

${ }^{53}$ Sirvan como ejemplo las alusiones al "cambio flexivo", "cambio derivativo" y otros tipo de "cambio" apuntados por García-Page (2008: 230 y ss.), en las que se dice, por ejemplo, que la forma fija de una estructura morfológica "tiene, en algunas ocasiones, una explicación histórica" (página 232), sin que encontremos más detalles sobre cuál sea tal explicación histórica, o se aventura en alguna ocasión la afirmación de que se ha producido la adjunción posterior de un afijo o seudoafijo a la base léxica poniendo como ejemplo el caso de "apostremas $(<$ a la postre $)$ " [sic] sin que se explique cuál es la razón de la mayor antigüedad de a la postre, pues apostremas se encuentra ya en la Primera Crónica General y en CORDE se puede encontrar abundante ejemplificación antigua; digamos al paso que no registra CORDE ningún caso de apostremas (ni a postremas, separado) en México, ni en Cuba ni en Ecuador, y es de presumir que tampoco para el resto de América, lo que no permite afirmar que apostremas sea posterior a a la postre, sino más bien al contrario. Otro tanto sucede cuando se habla de la selección de régimen preposicional en las unidades fraseológicas a lo largo del tiempo (página 233), que podría ser explicado unas veces como parte del proceso secular de fijación de preposiciones sustitutivas de los casos latinos en español (y, en general, en romance) en su sucesión diacrónica, mientras que se trataría de sustituciones ocasionales y aisladas en otras. Convendría distinguir entre unos y otros casos: los que son antiguos y han quedado fijados aisladamente en calidad de testimonios de una fase anterior de la lengua antes de su evolución en el proceso global común de las sucesivas etapas cronológicas, frente a las sustituciones que no implican necesariamente perspectiva diacrónica y pueden ser incluso variantes ocasionales libres y hasta individualidades, esto es, con un grado inexistente, mínimo o pequeño de institucionalización. 
No es gratuito realizar estas consideraciones, pues, en el trasvase recíproco vascocastellano de determinadas locuciones, el análisis de elementos prepositivos en romance se hace en forma pospositiva en su incorporación a la lengua vasca, por ser el vasco lengua de núcleo final ${ }^{54}$. Resultaría, a mi juicio, sumamente iluminador emprender un estudio sistemático de este trasvase vasco-románico: tomando como ejemplo la entrada manera en el Trilingüe de Larramendi se puede ver hasta qué punto, frente al laconismo de Landuchio, supera con creces incluso la deuda para con Autoridades al querer dejar constancia de la riqueza gramatical en él contenida al ser vertida al campo vasco.

Por otra parte, así como la teoría ha enriquecido considerablemente en los últimos tiempos el cultivo de la disciplina lexicográfica ${ }^{55}$, también es relativamente nueva la reflexión lingüística aplicada a la fraseología, o sea, la fraseografía ${ }^{56}$, que está contribuyendo a dotar de gran altura teórica a la inserción lexicográfica de unidades fraseológicas en todo tiempo ${ }^{57}$.

Pues bien, tras estos preliminares necesarios, quiero señalar ahora que me sumo plenamente a la reflexión que García-Page hace al hablar de las variantes fraseológicas cuando afirma que deben estar previstas, codificadas, fijadas de antemano, destacando que "la variación (autorizada) [sic] es, pues predecible"; añade que, por esa razón, las variantes están fijadas en la memoria colectiva y "suelen aparecer registradas en los diccionarios" Concuerdo plenamente con esta aseveración y veo en ella el fundamento básico para considerar necesario extraer la información que proporcionan los diccionarios históricos de todo tipo, entre ellos los bilingües y trilingües que contienen al español junto con el vasco. Si esta idea adquiere el suficiente relieve, será pilar de importancia para investigaciones futuras en el ámbito lexicográfico castellano y también vasco-románico ${ }^{59}$, y, si a esta consideración se suma la luz que los datos procedentes de la lexicografía pueden aportar al campo de las combinaciones pluriverbales, se verá que estamos ante un haz de intereses filológicos de implicación múltiple.

\footnotetext{
${ }^{54}$ Zabala y Odriozola (2004) las denominan "posposiciones sufijales"; v. también Echenique (en prensa-b).

${ }^{55}$ D. Azorín (2000: 11) ha señalado con acierto que la indagación historiográfica en España a fines del siglo XX ha contribuido grandemente a consolidar la importancia que la riqueza informativa contenida en los diccionarios entraña para diferentes aspectos del estudio lingüístico.

${ }^{56}$ V. Tristá Pérez (1999).

${ }^{57}$ V. Martín Zorraquino (2003).

${ }^{58} \mathrm{~V}$. García-Page (2008: 217, 286). Bien es verdad que no siempre ha sucedido así (equilicuá ha tenido escasa entrada en los diccionarios institucionales, por poner un ejemplo); por otra parte, no hay algunas veces soporte cierto para seleccionar el criterio codificador oportuno (por ausencia en la tradición); por lo bajinis-bajini-bajines muestra la necesidad tutorial que determine su carácter correcto-incorrecto sobre la base de la tradición histórica, para lo que sería muy beneficioso contar con un estudio histórico fraseológico del español amplio y metodológicamente bien elaborado.

${ }^{59}$ Como dijo R. Lapesa y ha recordado García-Page (2008: 283), "las locuciones viven en variantes", cita que se podría completar continuando el texto del propio Rafael Lapesa: "[las locuciones] viven rehaciéndose en continua transformación... son muchas las locuciones que se perpetúan con fluidez formal y aparición escrita ininterrumpida desde la Edad Media o el siglo XVI hasta ahora. Pero también hay casos de perduración en estado latente" (Lapesa, 1992 [1981]: 85). La propia Azorín (p. 187) ha señalado la importancia que da Autoridades en la microestructura al componente fraseológico, como, por otra parte, ha sido estudiado por V. Scandola (2006).
} 
2.1. La Fraseología histórica española implica en su análisis una línea plural de investigación en la que participan, al menos, la Historia de la codificación gramatical, la Lexicografía histórica (principalmente en lo que atañe a consideraciones metalexicográficas y metafraseográficas) y la Morfosintaxis histórica. En estas páginas trato de reflexionar sobre el proceso de incorporación de unidades fraseológicas de origen vasco y románico en la lexicografía vasca bilingüe y multilingüe de los siglos XVI al XVIII con el fin de llegar a conocer el camino seguido por ellas en diccionarios históricos del español ${ }^{60}$. Se persigue con ello un objetivo doble: por una parte, atender a su inserción fraseológica en la actividad lexicográfica de épocas pasadas y, por otra, así como de forma específica en este trabajo, extraer algunas muestras de la información que sobre el componente fraseológico del español está contenida en el conjunto de la producción lexicográfica señalada, ya que, como he indicado reiteradamente, la lexicografía histórica debería de ser una de las bases principales en el estudio de la Fraseología histórica ${ }^{61}$. Para indagar por este camino hay que sumar la perspectiva diacrónica al estudio lexicográfico y fraseográfico, sin olvidar que ambos se incluyen en la investigación gramaticográfica correspondiente, así como situar todo ello en la consideración teórica oportuna con el fin de aspirar, en última instancia, a la reconstrucción de la Diacronía fraseológica.

En otro lugar me he ocupado de las locuciones adverbiales de origen románico (Echenique, en prensa-b) incorporadas al euskera hablado y su registro en diccionarios como buena muestra del contacto vasco-románico. El presente trabajo pretende ser tan sólo un conjunto de reflexiones y apuntes sobre lo que cabría hacer en el ámbito de la lexicografía española si se tomara en consideración la existencia de diccionarios en los que el castellano aparece en compañía de la lengua vasca. Dada la amplitud del estudio fraseográfico, me limito a ofrecer en estas páginas algunas notas sobre aspectos concretos derivados de este campo, que podrían servir como punto de partida para reclamar la atención debida sobre la necesidad de llevar a cabo un estudio más completo, para lo que se necesitará tiempo y esfuerzo colectivo. No es este, por lo tanto, un estudio fraseográfico total de la parte castellana incluida en diccionarios bilingües o trilingües en que el español aparece en compañía de la lengua vasca, sino una serie de consideraciones iniciales que aportan alguna muestra de la incorporación lexicográfica de unidades fraseológicas en diccionarios vascos bilingües y trilingües, entendidas tan solo como pautas para un estudio posterior más completo. No en vano la labor lexicográfica es consecuencia de profunda reflexión sobre cada uno de los elementos insertos en el diccionario. La lexicografía es, de hecho, superación de la dualidad oralidad-escritura: coloquio y tradición escritural se aúnan

\footnotetext{
${ }^{60}$ Sirva de muestra la reciente contribución de F. J. Satorre Grau (2008); v. también Martín Zorraquino, quien ha ofrecido alguna muestra espléndida de este quehacer en 2003, bien es verdad que nuestra intención pretende remontarse en el tiempo hasta etapas más antiguas.

${ }^{61}$ Así se pone de manifiesto, por ejemplo, en el caso de la Fraseología histórica alemana, tal como puede verse en el trabajo "Historische Phraseologie" de Burger y Linke. Es curioso que este trabajo comience, a su vez, con el lamento de que no sea posible aún elaborar una historia completa de la fraseología alemana; claro que fue publicado en 1985, pero ya para entonces se había progresado notablemente en Fraseología (no tanto, empero, y de ahí la observación, en Fraseología histórica); pero es evidente que, si estamos en una época en la que se habla de lexicalización y gramaticalización, hay que hablar de fraseologización o de lexicalización fraseológica (como una forma de lexicalización) o de gramaticalización fraseológica (según los casos) en referencia a los procesos por los cuales se constituyen históricamente las unidades fraseológicas.
} 
para dar lugar al diccionario, que puede tener, eso sí, una orientación más o menos escorada hacia sus fuentes, más o menos libresca, según los fines que persiga ${ }^{62}$.

2.2. Podemos citar algún caso en proceso de fraseologización. Hoy, la lexicalización es total en la voz adiós, si bien todavía en el Diccionario panhispánico de dudas (s. v.) se dice que en algunos lugares de América se utiliza la grafía $a \operatorname{Dios}^{63}$, esto es, está sentida como unidad pluriverbal. En Landuchio, donde resulta llamativa la reducción de la entrada Dios, diosa, dioses en comparación con Nebrija, se lematiza en la voz Dios, al igual que en el Trilingüe de Larramendi, que ofrece la misma simplificación en relación con Autoridades, que sigue el mismo criterio lematizador; Pierre d'Urte, en cambio, registra adios, adiós, $a_{d i u} u^{64}$, sin indicio de pluriverbalidad. La voz, con las variantes adio, ario y adiu, ha tenido gran fortuna en el léxico vasco y seguramente ha sido recogida en sus diccionarios a partir de tradiciones lexicográficas diferentes ${ }^{65}$.

También el caso de apostremas, al que me he referido más arriba, parece ser lexicalización de a postremas y habría que analizar su relación con a la postre; tanto a postre, apostre, al postre, a la postre son menos tardíos de lo que apunta el DCECH (s. v. postrimero $^{66}$ ) por los datos que pueden verse en CORDE. Larramendi, por su parte, registra dexarlo para la postre, a puto el postre (cuya filiación latina denota su relación: lat. Infamis habeatur postremus), a la postre (con igual asociación latina: Ad extremum, ad postremum), por fin, y postre, además de postreramente, postrimeramente (ambos en la misma entrada, cuyos equivalentes en lat. son: Ultimo, postremo). Es clara la dependencia de Larramendi respecto de Autoridades en este caso, incluso en la parte latina.

Nebrija registra adesoras (Adesoras aduerbio.subito.repente y Adesoras adverbio deimprouiso), en tanto Landuchio ofrece a desoras (horda gachea, tempora vaga), donde es también distinta la equivalencia latina. Larramendi tiene diferente tradición, tanto castellana como latina (A deshora: desorduan, mugaitzean, adiuntza gaitzean desorenean. Lat. Intempestive), y la tradición que sigue no concuerda con Autoridades en este caso.

Landuchio recoge a la sazon, que no está en Larramendi. En el Suplemento está la voz sazon, pero no la locución; este dato es importante, porque permite constatar, si nos fijamos en la totalidad de su extensión, que en el Suplemento no se ha dado entrada a unidades pluriverbales, como si se hubiera completado pensando solamente en vocabulario sin implicaciones gramaticales. En el grueso de la obra, en cambio, la fraseología con más: a lo mas / poco más, o menos / ni mas, ni menos / las mas vezes / lo mas mas (gueyen gueyena.

\footnotetext{
${ }^{62}$ No deja de resultar curioso que, en un diccionario como el $D G V$ mencionado anteriormente, el lema vasco platillo se vierta al castellano como 'platillo'.

${ }^{63}$ V. adiós: "Interjección que se emplea como fórmula de despedida y que también puede expresar decepción, sorpresa, incredulidad o la irreparabilidad de un daño. Debe evitarse, por anticuada, la grafía a Dios". En Nieto y Alvar (2007), obra que habrá de contribuir notablemente al estudio minucioso de cuanto se dice en estas páginas, se lematiza en adiós, a pesar de ser abrumadora su documentación como a Dios, en tanto hay que buscar en postremo / postrema y deshora los testimonios correspondientes a apostremas y adeshoras.

${ }^{64}$ V. Urkizu (1989, I: 157).

${ }^{65} \mathrm{~V} . D G V$, s. v. adio.

${ }^{66}$ Se lee en $D C E C H$, s. v., "me parece claro que postre se sacó secundariamente de postrero según el modelo de cabo: cabero, tras: trasero, primo: primero".
} 
Lat. Ad sumum) / a mas tardar / de mas a mas / sin mas ni mas / a mas y mejor; con menos: a lo menos, por lo menos / lo menos / a lo menos / mucho menos / poco más, menos / ni más, ni menos /, y con otras muchas voces: a menudo, de mogollon, a montones, a prisa, a vezes / a las vezes / por vezes / de una vez / en vez de, de balde, en balde, de coraçon...es de enorme riqueza, de cuyo contraste con los matices apuntados en las equivalencia vascas podría obtenerse información de interés para el castellano. También es pertinente observar que algunas locuciones están presentes solo en Landuchio ( $a$ empujones) o solo en Larramendi (a escondidas, a escuras, a excuso).

2.2. El diccionario monolingüe constituye un mundo cerrado sobre sí mismo, esto es, sobre el sistema lingüístico al que se aplica con exclusividad, al tiempo que posee objetivo y estructura propios ${ }^{67}$. El diccionario bilingüe, por su parte, busca el establecimiento de equivalencias entre dos universos, a saber, los dos sistemas en los cuales queda centrado ${ }^{68}$. Frente a ellos, el trilingüe es, en principio, un diccionario multilingüe, que también puede abarcar algunas veces la estructura bilingüe, vertiendo las equivalencias de una lengua en otra $u$ otras. Hay que tener en cuenta que, en un diccionario bilingüe, y con mayor fundamento en uno trilingüe por la dificultad que representa a un único autor abarcar todos los campos comprendidos, cada parte tiene su propia historia, que puede llegar a afectar incluso al método mismo y a su aplicación. La Filología Vasca ha reconstruido bien, desde Michelena y sus continuadores, la tradición lexicográfica de la parte vasca de los diccionarios bilingües, trilingües y multilingües, lo que no quiere decir que no quede aún mucha tarea por delante; en cualquier caso, hay ya sentadas unas bases firmes para su estudio, tal como he señalado más arriba. También hay un conjunto relevante de estudios lexicográficos, a los que he aludido más arriba ${ }^{69}$. Ahora bien, dado que la tarea lexicográfica no suele partir de cero, sino que se inserta en una tradición, no es ocioso insistir en que queda todo por hacer en la parte castellana, latina y románica. Mi intención en este trabajo ha sido solo ofrecer algunas sugerencias de lo que resta por hacer con finalidad de marcar algunas pautas para que comiencen a ser tenidos en cuenta, dado que han estado muy desatendidos en los trabajos lexicográficos de ámbito hispánico, sin olvidar la tradición de la parte latina, que sigue siendo hoy una gran desconocida ${ }^{70}$.

Larramendi se inserta, creo, en la tradición académica española, pero no sabemos a ciencia cierta su filiación en la parte latina. Hay una tradición románica que arranca de Nebrija, cuya nomenclatura está en la base de Landuchio, quien de esta manera se inserta plenamente en la tradición nebrisense de larga secuela, pero hay locuciones adverbiales en Landuchio que no están en Nebrija. Larramendi, por su parte, arranca de la tradición académica; se aprecia con claridad que sigue a Autoridades en su Trilingüe, desde la misma ordenación alfabética de las voces, que va vertiendo al euskera y al latín. Queda por

\footnotetext{
${ }^{67}$ Véase Niederehe (1986) y Álvarez de Miranda (1995).

${ }^{68}$ Véase Hausmann y Werner (1991) y Werner (1991).

${ }^{69}$ V. la nota 13. Sirva como muestra la observación que sobre el valor del "Index uocabulorum aliquot Cantabricorum" de Bonaventura Vulcanius (1597), recogido en la tradición lexicográfica vasca desde Larramendi, al menos, hizo Luis Michelena en Estudio sobre las fuentes del Diccionario de Azkue (1970: 27), ampliada luego por Patricio Urquizu (1991: 27-28).

${ }^{70}$ En Satorre (2008) puede advertirse la peculiaridad de esta tradición, que debía tener su propia trayectoria en ámbito jesuita, lo que también afectaría a Larramendi.
} 
reconstruir el recorrido entre uno y otro autor, la tradición de la que parten y en la que se insertan los diccionarios bilingües y multilingües de ámbito vasco.

3. Final. A simple vista parece claro que la inclusión del vascuence en la lexicografía ha seguido un camino creciente en el transcurso del tiempo. Hoy se va conociendo mejor la trayectoria de la lexicografía vasca y de los esfuerzos por elevarla a la situación de lengua estándar, esfuerzos que tendrán su punto culminante en el siglo XVIII en la figura de Larramendi, si bien la estandarización del euskera tuvo que esperar hasta la segunda mitad del siglo XX. Ahora bien, las correspondencias lingüísticas en diccionarios tales no se dan solamente entre vasco y español, sino también entre vasco, español y otra u otras lenguas, de entre las cuales es el francés, por las razones históricas y geográficas aducidas más arriba, la más frecuente. En el presente trabajo se ofrecen algunas consideraciones tan solo sobre los diccionarios bilingües y trilingües en los que se incluye la lengua castellana, pero conviene no perder de vista otras implicaciones para investigaciones futuras, pues aún queda largo camino por recorrer antes de poder llegar a establecer la motivación que ha guiado el curso de los acontecimientos, esto es, la razón de las combinaciones seleccionadas con preferencia a la hora de confeccionar todos y cada uno de los diccionarios en los que está presente el euskera (dado que aparece por lo general en compañía de otras lenguas), así como el estudio detallado de la tradición o tradiciones lexicográficas de las que tales diccionarios proceden.

Por alguna razón aún no bien conocida, la consideración de estos diccionarios ha estado ausente en la tradición lexicográfica española y comenzamos ahora a entrar en una etapa en la que parece que van a ser tenidos en cuenta. Paulatinamente se va creando conciencia sobre esta cuestión; por poner ejemplos concretos, alguna noticia aporta Isabel Acero ${ }^{71} \mathrm{y}$ cabe destacar que G. Haensch y C. Omeñaca ${ }^{72}$ dedican, muy acertadamente, un capítulo de su libro a los diccionarios del español en contacto con las demás lenguas de España; es también muy ilustrativo el catálogo de diccionarios españoles elaborado en su día por $\mathrm{F}$. San Vicente ${ }^{73}$ para el siglo XVIII; ninguna alusión a tradiciones españolas distintas de la castellana encontramos, en cambio, en un libro, por otras razones excelente, como el de Azorín Fernández ${ }^{74}$. Convendría no olvidar, en este sentido, el resurgimiento proveniente de la consideración reciente de España como país multilingüe, con la atención prestada, en consecuencia, a las otras lenguas de España y a sus correspondientes procesos de creación de historiografía propia. Va siendo hora de rescatar su importancia, que, además, al reflejar una situación de contacto real con otra $\mathrm{u}$ otras lenguas (como es el caso del vasco hablado históricamente junto al castellano, navarro, aragonés, catalán, occitano o francés), trae aparejada, como consecuencia ineludible de ese contacto, información valiosa que habría que descodificar. El estudio vasco-románico encuentra en este campo motivo para su estudio conjunto. ¿En qué medida y de qué diccionarios castellanos, franceses o de otras

\footnotetext{
${ }^{71}$ V. I. Acero (2003: 203-204).

${ }^{72} \mathrm{~V}$. Haensch y Omeñaca (2005).

${ }^{73}$ V. San Vicente (1995).

${ }^{74}$ En efecto, en Azorín (2000) se habla de lexicografía bilingüe del español, pero nada se dice de los diccionarios en los que se contiene el euskera (bilingües, trilingües o multilingües), lo que no es probablemente sino una muestra de la falta de contacto habida en el pasado no tan lejano entre la Filología Vasca y la Filología Española.
} 
tradiciones son deudores los diccionarios vascos que conocemos, qué innovaciones metodológicas han introducido respecto a otros franceses, castellanos, catalanes, provenzales...? Y un largo etcétera de cuestiones. Dicho con otras palabras, queda aún prácticamente todo por hacer, con la ventaja, eso sí, de que ahora hay ya unas bases bien fundamentadas para emprender su estudio comparativo con el campo románico.

\section{REFERENCIAS BIBLIOGRÁFICAS}

ACERO, I. (2003). "La Lexicografía plurilingüe del español”. Lexicografía española, A. M. Medina Guerra (coord.), Barcelona, Ariel, 175-204.

Altuna, P. (1979). Etxepareren hiztegia. Lexicón Dechepariano, Bilbao.

AltunA, P. (1985). “Azpitarteren hiztegi argitaragabea Loiolan”. Symbolae L. Mitxelena Oblatae, Vitoria, 1097-1110.

Alvar, M. (1995). "Comentarios a la Gramática japonesa del Padre Oyanguren (1738)". Nebrija y Estudios sobre la Edad de Oro, Madrid, CSIC, 37-51.

Álvarez DE MirandA, P. (1992). "En torno al Diccionario de Terreros". Bulletin Hispanique 94/2, 559-572.

Álvarez DE MirandA, P. (1995). "Hacia una historia de los diccionarios españoles en la Edad Moderna”. Bulletin Hispanique 97/1, 187-200.

AzKarate, M. (1991). "Basque Lexicography". Wörterbücher. Dictionaries. Dictionnaires, Berlín / Nueva York, De Gruyter, t. III, 2371-2375.

AzKue, R. M. de (1969 [1905-1906]). Diccionario Vasco-Español-Francés, Bilbao, La Gran Enciclopedia Vasca, 2 vols.

AZORÍN FERNÁNDEZ, D. (2000). Los diccionarios del español en su perspectiva histórica, Alicante, Universidad de Alicante.

BARGAlló, M., J. GineBra (2002). "Doctrina sobre idiomaticidad y fraseología en algunas gramáticas catalanas y españolas de los siglos XVIII y XIX”. SEHL 2001. Estudios de Historiografía lingüística, M. Á. Esparza Torres, B. Fernández Salgado y H.-J. Niederehe (eds.), Hamburgo, H. Buske, 789-804.

Bosque Muñoz, I. (dir.) (2004). Las palabras en su contexto. REDES. Diccionario combinatorio del español, Madrid, SM.

Burger, H., A. LinKE (1985). "Historische Phraseologie". Sprachgeschichte. Ein Handbuch zur Geschichte der deutschen Sprache und ihrer Esforschung, W. Besch, O. Reichmann y S. Sonderegger (coord.), Berlín / Nueva York, W. de Gruyter, t. 2, 2018 2026.

CASARES, J. ( ${ }^{3} 1992$ [1950]). Introducción a la lexicografía moderna, Madrid, CSIC. 
Colón Doménech, G. (2002). Para la historia del léxico español, Madrid, Arco/Libros, 2 vols.

Corominas, J., J. A. Pascual Rodríguez (1980-1991). Diccionario Crítico Etimológico Castellano e Hispánico, Madrid, Gredos, 16 vols.

CORPAs PASTOR, G. (1996). Manual de fraseología del español, Madrid, Gredos.

CORPas Pastor, G. (ed.) (2003). Diez años de investigación en fraseología, análisis sintáctico-semánticos, contrastivos y traductológicos, Madrid, Iberoamericana; Frankfurt, Vervuert.

ECHENIQUE, M. T. (1985). "Campomanes y el proyecto de un gran diccionario vasco". Symbolae L. Michelena Oblatae, L. Melena (ed.), Vitoria, t. II, 1089-1095.

ECHENIQUE, M. T. ('1987 [1984]). Historia lingüistica vasco-románica, Madrid, Paraninfo.

ECHENIQUE ELIZONDO, M. T. (1998). "Los diccionarios trilingües en la lexicografía vasca: teoría y práctica de un ideal multisecular". Lexicografías iberrománicas: problemas, propuestas y proyectos, R. Werner y M. T. Fuentes (eds.), Frankfurt, Vervuert; Madrid, Iberoamericana, 33-48.

ECHENIQUe Elizondo, M. T. (2003). "Pautas para el estudio histórico de las unidades fraseológicas". Estudios ofrecidos al profesor J. J. de Bustos Tovar, J. L. Girón Alconchel, R. Santiago Lafuente y E. de Bustos Gisbert (eds.), Madrid, Universidad Complutense, 545-560.

EChEniQue Elizondo, M. T. (2008a). "La lengua vasca en la obra de Joan Coromines". Joan Coromines, vida y obra, A. M. Badia i Margarit y J. Solà (eds.), Madrid, Gredos, 482-506.

ECHENIQUe ElizONDO, M. T. (2008b). "Notas de sintaxis histórica en el marco del corpus de Diacronía fraseológica del español (DIAFRAES)". Romanische Syntax im Wandel, E. Stak, R. Schmidt-Riese y E. Stoll (eds.), Tubinga, Gunter Narr, 387-398.

ECHENIQUE ELIZONDO, M. T. (2008c). "Algunas notas sobre latín y romance en la fraseología hispánica medieval". Latin vulgaire - latin tardif VIII, Actes du VIIIe colloque international sur le latin vulgaire et tardif (Oxford, 6-9 septembre 2006), R. Wright (ed.), Hildesheim / Zúrich / Nueva York, Olms-Weidmann, 540-547.

ECHENIQUe Elizondo, M. T. (en prensa-a). "El estudio histórico de las unidades fraseológicas". Actas del XVI Congreso de la AIH (París 2007).

ECHENIQUe Elizondo, M. T. (en prensa-b). "Locuciones adverbiales de origen románico en la lengua vasca". Actas del XXV CILPR (Innsbruck 2007).

ECHENIQUe ELIZONDO, M. T. (en prensa-c). "Léxico vasco y latino-románico en contacto". Actas de II Jornadas Vasco-Románicas, Bilbao, Eusko Ikaskuntza-Sociedad de Estudios Vascos.

EChenique, M. T., J. SANChEZ (2005). Las lenguas de un Reino. Historia lingüistica hispánica, Madrid, Gredos. 
GAllinA, A. (1959). Contributi alla storia della lexicografía italo-spagnola dei secoli XVI e XVII, Florencia, Leo. S. Olschki.

GARcía-Page SÁnchez, M. (2008). Introducción a la Fraseología española. Estudio de las locuciones, Barcelona, Anthropos.

Giacalone de Ramat, A., P. Hopper (eds.) (1998). The limits of grammaticalization. Ámsterdam, J. Benjamins.

GómEZ, R. (2008). "Euskal gramatikagintza zaharraren historia laburra: XVII-XVIII. Mendeak". Gramática jaietan Patxi Goenagaren Omenez, X. Artiagoitia y J. A. Lakarra (eds.), Bilbao, Universidad del País Vasco, 329-349.

Gómez, R., J. A. LAKARra (1992). Euskalaritzaren historiaz, I: XVI-XIX mendeak, San Sebastián, Diputación de Guipúzcoa / Universidad del País Vasco.

GONZÁlez Ollé, F. (2004). "Navarra, Romania emersa y ¿Romania submersa?”. Aemilianense 1, 225-270.

Haensch, G., C. OMeñaCA (22005 [2000]). Los diccionarios del español en el siglo XXI, Salamanca, Universidad de Salamanca.

HAUSmanN, F. J. (1988). "Les dictionnaires bilingues (et multilingues) en Europe au XVIIIe siècle". La lexicographie française du XVIIIe au XXe siècle. Actes du Colloque International de Lexicographie, B. von Gemmingen y M. Hofler (eds.), París, 768-779.

HAUSMANN, F. J., R. O. WERNER (1991). "Spezifische Bauteile und Strukturen zweisprachiger Worterbucher: eine Ubersicht". Wörterbücher. Dictionaries. Dictionnaires, F. J. Hausmann, O. Reichmann, H. E. Wiegand y L. Zgusta (eds.), Berlín / Nueva York, 2729-2769.

Holtus, G. (1994). "Appunti sul concetto di plurilingüismo". Scritti di Linguistica e Dialettologia in Onore di Giuseppe Francescato, Trieste, 151-157.

IGLESIAS RECUERO, S. (2000). "La evolución histórica de pues como marcador discursivo hasta el siglo XV". BRAE, 209-307.

Kerejeta, M. J. (1991). “Ohienart Silvain Puovreaureen hiztegian”. ASJU 25/3, 865-899.

KNÖRR, E. (1987). Para una edición crítica del diccionario de Maurice Harriet. Tesis doctoral inédita, Vitoria.

KREFELD, Th. (2007). "La 'continuità' della Romania -e la storiografia delle lingue nazionali...". Mit Clio im Gerpräch. Romanische Sprachgeschichten und Sprachgeschichtsschreibung, J. Hafner y W. Oesterreicher (eds.). Tubinga, G. Narr, 6176.

LAKARRA, J. A. (1985). "Larramendiren hiztegigintzaren inguruan". Anuario del Seminario de Filología Vasca Julio de Urquijo 19/1, 9-50.

LAKARRA, J. A. (1991). “Testukritika eta hiztegiak: Harriet eta Larramendi”. Memoriae L. Mitxelena magistri sacrvm, 217-258. 
LAKARRA, J. A. (1992). "Larramendiren aurreko hiztegigintzaren historiaz: aztergai eta gogoeta". Manuel Larramendi. Hirugarren mendeurrena (1690-1990), J. A. Lakarra (ed.), Andoain, Ayuntamiento de Andoain.

LAKARRA, J. A. (1993a). "Hirur lengoaietan tresora: hiztegigintzaren historia eta tipologia". Anuario del Seminario de Filología Vasca Julio de Urquijo 27/3, 50-78.

LAKARrA, J. A. (1993b). XVIII. Mendeko hiztegigintzaren etorkiez. Tesis doctoral inédita, Vitoria, Universidad del País Vasco.

LAKARRA, J. A. (1995). Harrieten gramatikako hiztegiak (1741), San Sebastián, Diputación Foral de Guipúzcoa.

LAPESA, R. (1992 [1980]). “Alma y ánima en el Diccionario Histórico de la lengua española”. Léxico e historia. II. Diccionarios, Madrid, Istmo, 65-78.

LAPESA, R. (1992 [1981]). “Alma y ánima en el Diccionario Histórico de la Lengua Española: su fraseología”. Léxico e historia. II. Diccionarios, Madrid, Istmo, 79-86.

LARRAMENDI, M. ( ${ }^{2} 1984$ [1745]). Diccionario trilingue del castellano, bascuence y latín, San Sebastián, Diputación de Guipúzcoa.

LePINETTE, B. (1992). "La postérité lexicographique de Nebrija. Les Vocabularius Nebrissensis latin-français (1511-1541)”. HL 19, 227-260.

Martín Zorraquino, M. A. (2001). "Sobre la gramaticalización de desde luego". Actes $d u$ XXIIème Congrès International de Linguistique et Philologie Romanes, Tubinga, M. Niemeyer, t. III, 845-857.

MARTín ZorRAQuino, M. A. (2003). "La inserción léxica de desde luego". Lexicografía y Lexicología en Europa y América. Homenaje a Günther Haensch en su 80 aniversario, M. T. Echenique y J. Sánchez (eds.), Madrid, Gredos, 186-199.

MARTínez MARÍn, J. (1996). Estudios de fraseología española, Málaga, Ágora.

MARTínez Montoro, J. 2001. "La fraseología en los diccionarios del español anteriores al siglo XX”. SEHL 2001. Estudios de Historiografía lingüística, M. A. Esparza Torres, B. Fernández Salgado y H.-J. Niederehe (eds.), Hamburgo, H. Buske, 906-923.

Medina Guerra, A. M. (coord.) (2003). Lexicografía española, Barcelona, Ariel.

MENDíVIL, J. L. (1999). Las palabras disgregadas. Sintaxis de las expresiones idiomáticas y los predicados complejos, Zaragoza, M. Pons.

Michelena Elissalt, L. ( ${ }^{3} 1985$ [1960]). Fonética Histórica Vasca, San Sebastián, Diputación de Guipúzcoa.

Michelena Elissalt, L. (1960a). Historia de la literatura vasca, Madrid, Minotauro.

Michelena Elissalt, L. (1960b). Prólogo a la $2^{\text {a }}$ edición del Lexicón bilbaíno de E. de Arriaga, Madrid, Minotauro. 
Michelena Elissalt, L. (1970). Estudio sobre las fuentes del diccionario de Azkue, Bilbao, Publicaciones del Centro de Estudios Históricos de Vizcaya (Real Sociedad Vascongada de Amigos del País).

MichelenA, L. (1985). Lengua e historia. Madrid.

MichelenA, L. (1988). Sobre historia de la lengua vasca, J. Lakarra (ed.), San Sebastián.

Michelena Elissalt, L. (1988). Palabras y textos, Bilbao / Vitoria, Universidad del País Vasco.

MichelenA, L., M. Agud (1957). Nicolao Landucci. Dictionarium Linguae Cantabricae (1562), San Sebastián, Diputación de Guipúzcoa.

Michelena, L., I. SARAsola (1987-2004). Diccionario general Vasco / Orotariko Euskal Hiztegia, Bilbao, Desclée De Brouwer, Mensajero, 16 vols.

Montoro DEL ARCO, E. T. (2002). "La fraseología en la tradición gramatical española". SEHL 2001. Estudios de Historiografía lingüistica, M. A. Esparza Torres, B. Fernández Salgado y H.-J. Niederehe (eds.), Hamburgo, H. Buske, 926-942.

NebriJA, E. A. (1979). Diccionario latino-español (Salamanca,1492). Estudio preliminar por G. Colón y A. Soberanas. Barcelona.

NiEDEREHE, H.-J. (1986). "Das Universal Vocabulario des Alfonso Fernández de Palencia (1490) und seine Quelle". The History of Linguistics in Spain, A. Quilis y H.-J. Niederehe (eds.), Ámsterdam, 39-54.

Nieto JimÉnez, L., M. Alvar EzQuerra (2007). Nuevo Tesoro Lexicográfico del español (S. XIV-1726), Madrid, Real Academia Española, Arco / Libros, 11 vols.

OYHARÇABAL, B., (1989). "Les travaux de grammaire basque avant Larramendi (1729)". ASJU 23, 59-73. Después en R. Gómez y J. A. Lakarra (eds.), 91-105.

PeILlen, Tx. (1983). "Belako zaldunaren zuberotar hiztegia XVIIII. mendean”. Fontes Linguae Vasconum 25, 127-146.

Pons BorderíA, S., L. RuIZ GuRILlo (2001). "Los orígenes del conector de todas maneras: fijación formal y pragmática". $R F E$ 81, 317-351.

Real ACAdEmia ESPañola. Corpus de Referencia del Español (CORDE).

REAL ACADEMia EsPañola / Asociación DE ACADEMias DE LA LENGUA EsPañola (2005). Diccionario panhispánico de dudas, Madrid, Santillana.

Ruiz Gurillo, L. (1998). Aspectos de fraseología española, Valencia, Cuadernos de Filología.

RUIZ GuRILlo, L. (2000). "Un enfoque didáctico de la fraseología española para extranjeros". Espéculo, Universidad Complutense.

SAN VICENTE, F. (1995). Bibliografia de la lexicografía española del siglo XVIII. Bolonia. 
SARASOLA, I. (1980). Materiales para un thesaurus de la lengua vasca. Tesis doctoral inédita, Barcelona.

SARASOLA, I. (1996). "Lexicografía vasca: el Diccionario general Vasco". Actas do Simposio de Lexicografia actual: elaboración de diccionarios, Cadernos de lingua, A Coruña, Real Academia Galega.

SARASOLA, I. (2008). "Iparraldeko hiztegigintza Larramendiren paradigmaren garaian". Gramática jaietan Patxi Goenagaren Omenez, X. Artiagoitia y J. A. Lakarra (eds.), Bilbao, Universidad del País Vasco, 769-784.

SATORRE GRAU, F. J. (2008). "Las locuciones adverbiales en la lexicografía hispano-latina del Siglo de Oro". Actas del VII Congreso Internacional de Historia de la Lengua Española, Madrid, Arco / Libros, 1125-1136.

SCANDOla, V. (2006). El tratamiento de la fraseología en los diccionarios de la Real Academia Española 11726-2001): análisis fraseológico y fraseográfico. Contribución a la historia de la fraseología española. Tesis doctoral inédita, Universitat de València.

Seco, M., O. Andrés, G. RAmos (2004). Diccionario fraseológico documentado del español actual, Madrid.

TrASK, R. (1997). The History of Basque, Londres / Nueva York, Routledge.

TristÁ PÉreZ, A. M. (1999). "La fraseología y el Diccionario de fraseología cubana". Lexicografías iberorrománicas: problemas, propuestas y proyectos, T. Fuentes y R. Werner (eds.), Frankfurt, Vervuert; Madrid, Iberoamericana, 169-184.

URgELl, B. (1997). "Estudios en torno a la historia de la lexicografía vasca". ASJU 31/2, 643-667.

URgell, B. (1998a). "Hiztegi Hirukoitza eta Diccionario de Autoridades erkatuaz: oinarrizko ezaugarri zenbait" (I). ASJU 32/1, 109-163.

Urgell, B. (1998b). "Hiztegi Hirukoitza eta Diccionario de Autoridades erkatuaz: sarreraren edukia" (II). ASJU 32/2, 365-414.

Urgell, B. (1999). "Hiztegi Hirukoitza eta Diccionario de Autoridades erkatuaz: Gaztelania” (III), ASJU 33/1, 157-238.

Urgell, B. (2000). Hiztegi Hirukoitza-ren osagaiez. Tesis inédita, Universidad del País Vasco / Euskal Herriko Unibertsitatea.

Urgell, B. (2004). "Etimologia eta hitz sorkuntza Larramendiren Hiztegi Hirukoitz-ean". Lapurdun 9, 299-310.

URGELL, B. (2008). "Berriemaileen gaitasuna eta eredu lexicografikoaren eragina Landucciren hiztegian". Gramática jaietan Patxi Goenagaren Omenez, X. Artiagoitia y J. A. Lakarra (eds.), Bilbao, Universidad del País Vasco, 805-835.

URQUiJO, J. de (1925). “¿Cuál es el primer texto vasco impreso conocido?”. RIEV 16, $477-$ 491. 
UrkizU, P. (1989). Pierre D’Urteren hiztegia, San Sebastián, Mundaiz, 2 vols.

URQUIZU, P. (1991). Introducción a la Filología Vasca, Madrid, UNED.

VAREla, F., H. Kubarth (1996). Diccionario fraseológico del español moderno, Madrid, Gredos.

VERDONK, R. A. (1979). "Contribución al estudio de la lexicografía española en Flandes en el siglo XVII (1595-1707)”. BRAE 59, 289-369.

WERNER, R. (1991). “Die Markierungen im zweisprachigen Wörterbüch”. Wörterbücher. Dictionaries. Dictionnaires, F. J. Hausmann, O. Reichmann, H. E. Wiegand y L. Zgusta (eds.), Berlín / Nueva York, 2796-2803.

Werner, R. O., F. J. Hausmann. V. Hausmann.

WotJAK, G. (coord.) (1998). Estudios de fraseología y fraseografía del español actual. Frankfurt, Vervuert; Madrid, Iberoamericana.

ZABALA, I., J. C. ODRIOzOLA (2004). "Los complejos posposicionales en vasco". Las fronteras de la composición en lenguas románicas y en vasco, E. Pérez Gaztelu, I. Zabala y Ll. Gràcia (eds.), San Sebastián, Universidad de Deusto, 281-316.

ZUAZO, K. (22004 [2003]). Euskalkiak, Herriaren lekukoak, San Sebastián, Elkarlanean.

ZUAZO, K. (2008). Euskalkiak. Euskararen dialektoak, San Sebastián, Elkar.

ZuluagA, A. (1981). Introducción al estudio de las expresiones fijas, Tubinga, M. Niemeyer.

Zuluaga, A. (1992). "Spanische Phraseologie". Lexikon der Romanistischen Linguistik, G. Holtus, M. Metzeltin y Ch. Schmitt (eds.), Tubinga, M. Niemeyer, t. I, 125-131.

$\mathrm{M}^{\mathrm{a}}$ Teresa Echenique Elizondo

Teresa.Echenique@uv.es

Departamento de Filología Española

Facultad de Filología, Traducción e Interpretación

Avda. de Blasco Ibáñez, 32

E-46010 Valencia 